ISSN on-line: 1982-9949

Doi: $10.17058 /$ rea.v23i3.6147
A matéria publicada nesse periódico é licenciada sob forma de uma Licença Creative Commons -Atribuição 4.0 Internacional http://creativecommons.org/licenses/by/4.0/"

\title{
DISCIPLINA DE LIBRAS: O QUE AS PESQUISAS ACADÊMICAS DIZEM SOBRE A SUA INSERÇÃO NO ENSINO SUPERIOR?
}

Angela Nediane dos Santos ${ }^{1}$

Madalena Klein ${ }^{2}$

\section{Resumo}

O artigo analisa como a inserção da disciplina de Libras - Língua Brasileira de Sinais - no Ensino Superior vem sendo foco de pesquisas desde o Decreto Federal no 5.626/2005. Realizamos a busca em diferentes sites de pesquisa, como o Scielo e o Google, encontrando dissertações e teses, bem como artigos disponibilizados em livros, revistas ou anais de eventos. Verificamos que essas produções analisam: a legislação enquanto política que obriga a inserção da disciplina no Ensino Superior; os currículos a partir de planos de ensino das disciplinas; as implicações da disciplina na formação de professores para atuarem com alunos surdos na inclusão; a formação do professor de Libras no Ensino Superior; os materiais didáticos para a disciplina de Libras. São efervescentes os discursos em torno da disciplina de Libras, produzindo

1Doutoranda em Educação pelo Programa de Pós-Graduação em Educação da Faculdade de Educação da Universidade Federal de Pelotas. Professora da Área de Libras, do Centro de Letras e Comunicação, da Universidade Federal de Pelotas. Participante do GIPES - Grupo Interinstitucional de Pesquisas em Educação de Surdos. Endereço: Rua Gomes Carneiro, $\mathrm{n}^{\mathbf{0}}$ 1, CEP 96010-610, Pelotas-RS, Brasil. Endereço eletrônico: angelanediane@gmail.com

2Doutora em Educação. Professora do Programa de Pós-Graduação em Educação da Faculdade de Educação da Universidade Federal de Pelotas, na linha de Pesquisa Currículo, Profissionalização e Trabalho Docente. Pesquisadora do GIPES - Grupo Interinstitucional de Pesquisas em Educação de Surdos. Endereço: Rua Alberto Rosa, nº 154, CEP 96101-770, Pelotas-RS, Brasil. Endereço eletrônico: kleinmada@ hotmail.com 
DISCIPLINA DE LIBRAS: O QUE AS PESQUISAS ACADÊMICAS DIZEM SOBRE A SUA INSERÇÃO NO ENSINO SUPERIOR?

significados sobre os surdos, sua língua e sua educação e efeitos nos próprios currículos da disciplina.

Palavras chave: Disciplina de Libras; Ensino Superior; Pesquisas Acadêmicas

\section{INTRODUÇÃO}

Este artigo tem por foco analisar como a disciplina de Língua Brasileira de Sinais - Libras - vem sendo alvo de pesquisas acadêmicas e de que modo tais pesquisas se tornam discursos que circulam e produzem efeitos nos currículos das referidas disciplinas. Trata-se de um recorte de uma pesquisa que objetiva investigar, em universidades federais de diferentes regiões brasileiras, os programas analíticos das disciplinas de Libras dos currículos dos cursos de licenciatura, buscando recorrências e rupturas, no intuito de discutir e analisar os discursos que tais disciplinas fazem circular e que efeitos tais discursos têm na formação de professores.

Desde dezembro de 2005 a disciplina de Libras - Língua Brasileira de Sinais - deve compor obrigatoriamente os currículos dos cursos de Licenciatura e Fonoaudiologia, conforme determina o Decreto Federal $n^{\circ} 5.626 / 2005^{3}$ (BRASIL, 2005). Entendemos ser importante compreender e problematizar como esta disciplina vem se constituindo e que efeitos vêm provocando, em termos políticos e curriculares, nesses primeiros dez anos de implantação, inclusive para proporcionar outras pesquisas futuramente.

Cabe salientar que antes mesmo da promulgação do decreto federal $n^{0} 5.626 / 2005$, o ensino da Libras já acontecia em diferentes níveis de ensino e de espaços educativos, sendo essas práticas alvo de pesquisas. Um exemplo é o artigo Questões preliminares sobre o ensino de língua de sinais a ouvintes: reflexões sobre a prática ${ }^{4}$ (LACERDA, CAPORALI, LODI, 2004), que teve como propósito discutir aspectos relativos ao ensino da Libras como segunda língua, para ouvintes, buscando contribuir para a implementação da proposta de abordagem bilíngue. Ali,

\footnotetext{
${ }^{3}$ O Decreto Federal no 5.626 de 22 de dezembro de 2005 regulamenta a Lei Federal no 10.436 de 10 de abril de 2002 , que reconhece a Língua Brasileira de Sinais - Libras - como língua da comunidade surda brasileira.

${ }^{4}$ Os títulos das publicações que serão descritas neste artigo serão grifados em itálico para se diferenciarem do corpo do texto.
} 
SANTOS, A. N.; KLEIN, M.

as autoras apresentam reflexões sobre os diferentes modos como a Libras vinha sendo ensinada até aquele momento.

Interessou-nos uma aproximação a essas pesquisas sobre o ensino de Libras, procurando conhecer o foco das investigações, bem como as abordagens analíticas utilizadas. Na sequencia, apresentamos alguns dos resultados atingidos em nossa analise das produções acadêmicas que tematizam a disciplina de Libras nos currículos de cursos no ensino superior. A busca foi realizada em diferentes sites de pesquisa como o Scielo e o Google, bem como a partir das próprias indicações bibliográficas contidas nos artigos lidos. Tais pesquisas estão disponibilizadas em forma de artigos que compõem livros, revistas ou anais de eventos, ou em forma de dissertação de mestrado. Não privilegiamos um único espaço de pesquisa ou uma única forma de publicação. Independentemente de onde tenha sido publicado, o interesse se deu naquilo que está sendo alvo de pesquisas e discussões quando o foco é a disciplina de Libras inserida no Ensino Superior.

\section{OS FOCOS DAS PESQUISAS SOBRE A DISCIPLINA DE LIBRAS NO ENSINO SUPERIOR}

Em uma primeira aproximação às produções acerca da disciplina de Libras no ensino superior pudemos verificar que grande parte dessas produções se ocupa: a) da análise da legislação, como política que obriga a inserção da disciplina de Libras no Ensino Superior; b) de análises curriculares, as quais descrevem e comparam os planos de ensino das disciplinas de Libras; c) das implicações da disciplina de Libras no que se refere especificamente à formação de professores para atuar com alunos surdos na inclusão; d) de análises sobre a formação do professor de Libras no Ensino Superior; e, ainda, e) de análises dos materiais didáticos para o ensino da disciplina de Libras, entre outros. Assim, nas publicações encontradas, a disciplina de Libras é pesquisada a partir destes cinco focos principais, que passamos a apresentar a seguir de forma mais detalhada.

\subsection{Foco na análise da política de inserção da disciplina no ensino superior}


DISCIPLINA DE LIBRAS: O QUE AS PESQUISAS ACADÊMICAS DIZEM SOBRE A SUA INSERÇÃO NO ENSINO SUPERIOR?

Com ênfase no primeiro foco - análise da política - encontramos o artigo de Martins (2008), Análise das vantagens e desvantagens da Libras como disciplina curricular no ensino superior que se baseia nas análises críticas à historiografia centralizadora de De Certeau (1995). De acordo com a autora "pesquisas que se voltem às histórias de lutas de diferentes sujeitos pelo descentramento do poder, vêm ao encontro às propostas políticas de De Certeau (1995) às minorias." (MARTINS, 2008, p. 192). Mais especificamente a autora se propõe a analisar os discursos políticos contidos no Decreto 5.626/2005 e seus atravessamentos sociais, pensando

[...] a dupla articulação da inclusão da disciplina de Libras na instituição superior: como promotora de visibilidade lingüística às diferenças surdas, de um lado, mas de outro possível agenciadora do discurso de uma hostil inclusão que mascara politicamente as mudanças que seriam, de fato, necessárias na sala de aula e no currículo, mantendo e contribuindo com um discurso e apelo de atos "politicamente corretos". (MARTINS, 2008, p. 194)

Ela aponta algumas vantagens da promulgação do Decreto Federal $n^{\circ} 5.626 / 2005$, quais sejam: “[...] ter sido a resposta das lutas surdas [...] [; oferecido] hospitalidade para o surdo usufruir sua língua [...] [; possibilitado] a hospitalidade do surdo entre os ouvintes [...] permitindo, através do uso político, abrir espaços de lutas e fazer surgir a identidade cultural dos surdos em meios favoráveis ao desenvolvimento de seu potencial.” (MARTINS, 2008, p. 198). Além disso, aponta o aumento dos surdos nas instituições de ensino superior, tanto como estudantes, quanto como docentes e pesquisadores. Assim, segundo a autora, a legislação atual é "promotora de descentramentos", na medida em que "[...] oferece ao surdo um lugar de discurso, o poder da fala e a autoridade no processo do ensino de ouvintes" (idem, p. 199).

A autora também aborda as desvantagens, baseando-se no artigo "Língua e cultura no plural - pela resistência à folclorização do outro", de Souza e Gallo (2007). As desvantagens são, segundo Martins (2008, p. 202-203):

[...] a comercialização da Libras como instrumento com fins políticos centralizadores, mantendo ponte apenas ao ensino da oralidade; a possível e sutil paralisação das resistências surdas pela ilusão de "trabalho cumprido", movimento perverso, podendo lentamente provocar o enfraquecimento da cultura e identidade surda se colocada apenas como uma língua memorável onde os sujeitos surdos não se identificam mais; ainda, os perigos de transformarmos a disciplina de Libras num manual de ensino rápido que 
SANTOS, A. N.; KLEIN, M.

facilita e promove, por si, o acesso à inclusão - seríamos assim traídos pois de fato não é esse o intuito.

Martins (2008, p. 195) salienta que pode se tornar "superficial o ensino da língua de sinais, tomando uma única disciplina semestral, como manual de inclusão dos surdos na escola e na sociedade".

Em 2012, a autora dá continuidade a essas discussões publicando o artigo $O$ acontecimento do ensino de libras - diferenças e resistências, no livro Libras em estudo: ensinoaprendizagem, organizado por Neiva de Aquino Albres. Neste artigo Martins aborda alguns aspectos políticos que fizeram emergir o ensino da Libras como disciplina curricular, problematizando a formação de educadores de surdos (pedagogia bilíngue), de educadores surdos (licenciatura), e, sobretudo, de professores para o ensino da Libras.

Martins finaliza o artigo indagando sobre como poderemos escapar ao barateamento e à folclorizacão da língua de sinais e dos movimentos surdos?

\subsection{Foco nas análises dos currículos das disciplinas de Libras}

Em relação ao segundo foco - análises curriculares - destacamos a dissertação de Mestrado de Terezinha Pereira, intitulada Os desafios da implementação do ensino de Libras no Ensino Superior (PEREIRA, 2008). A pesquisa objetiva descrever e analisar o processo de implementação do ensino de Libras no ensino superior em oito instituições universitárias, circunscritas em cidades do interior de São Paulo e de Minas Gerais. Os dados foram coletados por entrevistas semiestruturadas com dez coordenadores de cursos de formação de professores. Os resultados indicaram que até 2008, dos dez cursos, quatro implementaram o ensino de Libras e quatro apenas incluíram Libras em suas propostas curriculares. A autora observou que, nos cursos que implementaram o ensino de Libras, dois deles são ministrados por professor surdo, com aprovação em exame de proficiência do Ministério da Educação e Cultura - MEC, e, os outros dois, por professor fluente em Libras. Um dos resultados apontados pela autora na conclusão é: "Observou-se que a disciplina Libras, está sendo disponibilizada no $4^{\circ}$ e no $5^{\circ}$ 
período, tornando-se desconectada do restante da matriz curricular” (PEREIRA, 2008, p. 79), sendo a única disciplina que aborda a temática da educação de surdos nos referidos cursos.

Lemos e Chaves (2012) publicaram nos Anais do XVI ENDIPE - Encontro Nacional de Didática e Práticas de Ensino - o artigo A disciplina de Libras no ensino superior: da proposição à prática de ensino como segunda língua. Eles apresentam um estudo de análise comparativa de ementas e dos conteúdos de disciplinas de Libras ministradas em seis Instituições de Ensino Superior, localizadas em quatro regiões brasileiras. Em suas análises eles perceberam:

[...] um enfoque descritivo e, às vezes, classificatório dos conteúdos teóricos e práticos sobre a surdez e a Libras; certo engessamento na seleção do conteúdo, refletindo, sobremaneira, a sequência do modelo apresentado no curso básico "Libras em Contexto" [de Tânya Amara Felipe (2005)]; maior distribuição do conteúdo para discussão sobre a língua e a surdez em detrimento ao ensino da Libras. (LEMOS; CHAVES, 2012, p. 002285)

Os autores observaram que tanto as ementas quanto os conteúdos propostos nos planos de ensino são muito similares nas seis IES analisadas. É nítida a separação entre conteúdos práticos - focados na aprendizagem de vocabulário em Libras - e teóricos, no entanto, nenhum programa deixa claro o tempo dispensado para cada um dos aspectos. Também constataram que não há diferenciação dos conteúdos da disciplina de Libras por curso, sendo a mesma disciplina ministrada para todos os cursos.

Também com foco nos planos de ensino da disciplina de Libras, Edna Aparecida Mercado (2012) realizou uma pesquisa comparativa entre os planos desta disciplina em cinco cursos de Pedagogia de algumas instituições privadas de ensino superior da grande São Paulo, referentes ao ano de 2009. No artigo $O$ significado e implicações da inserção de libras na matriz curricular do curso de pedagogia, a autora avaliou os significados e implicações da inserção desta disciplina na matriz curricular do curso de pedagogia. A análise se deu no sentido de:

[...] constatar se a organização apresentada nos planos de ensino da disciplina Libras é satisfatória para corresponder ao proposto pelo Decreto no. 5626/055, bem como, as necessidades de conhecimento do professor, para atender o aluno surdo, em seu processo de aprendizagem. (MERCADO, 2012, p. 62). 
SANTOS, A. N.; KLEIN, M.

Em todos os planos de ensino analisados aparece a abordagem teórica e prática da Libras, sendo que nesta última são recorrentes os termos "rudimentos de Libras" ou "vocabulário básico", o que Mercado (2012) considera insuficiente para formar professores bilíngues, conforme determinaria o decreto federal $n^{o}$ 5.626/2005. A autora infere que "[...] apesar de objetivar a preparação do professor para incluir o surdo na escola regular e desenvolver sua alfabetização, percebe-se que a organização dos planos não permite a efetivação desses objetivos" (idem, p. 66). A pesquisa concluiu que, dentre as problemáticas existentes no processo de implementação da disciplina, a pouca carga horária e a falta da sistematização dos conteúdos são as mais graves, denunciando a ausência de uma formação que proporcione ao pedagogo condições mínimas de atuar na perspectiva bilíngue de educação de surdos.

Tendo por ênfase as análises descritivas dos programas das disciplinas de Libras, também encontramos o trabalho Perspectiva sociolinguística da inclusão da Libras no ensino superior, de Fossile e Venâncio (2013). Eles realizaram uma análise dos Projetos Pedagógicos dos Cursos de Licenciatura em História e Letras da Universidade Federal do Tocantins (UFT) - Campus de Araguaína, no intuito de refletir sobre a maneira como os cursos superiores estão lidando com a inclusão da Libras em suas grades curriculares. Tais projetos passaram por um processo de reformulação e foram aprovados em 2009. Segundo as autoras a disciplina de Libras é obrigatória em ambos os cursos, tendo carga horária (60 horas), objetivo, ementa, conteúdos e bibliografia idênticos. A diferença é que no Curso de Letras ela é ofertada no $4^{\circ}$ período e no Curso de História no $7^{\circ}$ período. Elas observam que, no momento da escrita do artigo, a disciplina ainda não tinha sido ministrada para ambos os cursos e que ainda não havia professor para ministrar esta disciplina no referido Campus daquela Universidade. Além da disciplina de Libras, os cursos de Letras e História oferecem uma disciplina que aborda a inclusão em seu rol de disciplinas optativas/eletivas. O curso de Letras tem também, além das disciplinas citadas, uma disciplina obrigatória que aborda aspectos relativos à inclusão educacional de pessoas com necessidades especiais.

No artigo A disciplina de Língua Brasileira de Sinais nos currículos dos cursos de Pedagogia, publicado pelas professoras Célia Vitalino, Maria Julia Dall’Acqua e Sônia Maria Brochado (2013), elas buscam caracterizar como as Instituições de Ensino Superior públicas dos Estados de São Paulo e do Paraná estão organizando a disciplina de Libras nos cursos de 
DISCIPLINA DE LIBRAS: O QUE AS PESQUISAS ACADÊMICAS DIZEM SOBRE A SUA INSERÇÃO NO ENSINO SUPERIOR?

Pedagogia, a partir das determinações contidas na Lei $\mathrm{n}^{\mathrm{o}} 10.436 / 2002$. As autoras coletaram as ementas da disciplina de Libras disponíveis nos projetos curriculares de 25 cursos presenciais de Pedagogia de Instituições de Ensino Superior - IES - públicas do Paraná e São Paulo. Elas concluem que no Paraná a maioria das IES prevê a inclusão da disciplina de Libras, já em São Paulo, apenas 60\%. A carga horária dessas disciplinas varia de 30 a 102 horas, mas a maioria tem em torno de 60 horas. Esta carga horária ora é caracterizada como prática, ora como teórica e por vezes teórico/prática. Segundo as autoras,

[...] os dados evidenciam que os formadores responsáveis pela elaboração das ementas, em sua maioria, consideram importante que o ensino da Libras se dê atrelado ao conhecimento sobre a cultura surda, o processo de interpretação Libras-Português / Português-Libras, bem como sobre os múltiplos aspectos envolvidos no processo educacional da pessoa surda, especialmente o bilinguismo e o processo de inclusão. (VITALINO, DALL'ACQUA e BROCHADO, 2013, p. 119).

\subsection{Foco na formação de professores}

Como terceiro foco das publicações encontradas destaca-se a análise das contribuições da disciplina de Libras na formação de professores para atuar com alunos surdos na educação inclusiva. Rossi publicou em 2010 o artigo A Libras como disciplina no ensino superior, tratando especificamente da relevância desta disciplina na formação de professores que atuarão na inclusão. Ela recorre à Vigotsky e Bakhtin para ressaltar a importância da Libras na vida escolar dos alunos surdos que encontram-se em processo de inclusão, especialmente no que se refere à sua aprendizagem. Desse modo, é preciso que o professor esteja preparado, e para tanto é imprescindível que ele saiba se comunicar com estes alunos, usando a Libras. De acordo com Rossi (2010, p. 70) o Decreto Federal no 5.625/2005 considera a dimensão linguística para a inclusão do aluno surdo na escola regular, tendo em vista que obriga a inserção da disciplina de Libras nos cursos que formam professores. Ao inserir a disciplina de Libras nos cursos de licenciatura já se deu um grande passo rumo à efetivação da inclusão, considerando-se que ter uma língua compartilhada entre professor e aluno é fundamental para que haja aprendizagem. No entanto, ela aponta que só esta inserção não garante a inclusão. Além disso ela ressalta que o 
SANTOS, A. N.; KLEIN, M.

Decreto não menciona como esta disciplina deve ser, que conteúdos devem ser ensinados, com quais objetivos e com qual carga horária.

Em 2011 a Professora Ana Cláudia B. Lodi e a bolsista de iniciação científica Érica A. Nogueira publicaram o artigo Língua Brasileira de Sinais nos Cursos de Licenciatura: investigando o processo de formação de professores. Trata-se de uma pesquisa realizada com alunos da disciplina "Introdução à Língua Brasileira de Sinais", no ano de 2010 - primeira vez que esta disciplina foi ministrada para Cursos de Licenciatura da Universidade de São Paulo Campus Ribeirão Preto. Estes alunos responderam questionários no início e no final da disciplina. A pesquisa objetivou investigar as possíveis transformações que a referida disciplina possibilita no que diz respeito à formação profissional dos alunos para futura atuação como professor junto a alunos surdos, em salas de aula inclusivas. As autoras concluíram que, além de conhecerem aspectos específicos à cultura surda, à comunidade surda e aos sujeitos surdos, a disciplina contribui significativamente com a sua formação docente, por ofertar elementos para atuar e se comunicar com alunos surdos. Também inferem que ao final da disciplina os alunos assumem um posicionamento mais crítico em relação à forma como a inclusão educacional vem ocorrendo. Além disso, também observaram que é necessário um aumento da carga horária da disciplina de Libras, que à época era de apenas 30 horas.

No mesmo ano, Machado e Lírio publicaram o artigo A disciplina de libras e a formação inicial dos professores: experiências dos alunos de graduação em pedagogia na Universidade Federal do Espírito Santo. Apresentam uma pesquisa de iniciação científica cujo foco está na percepção dos acadêmicos deste curso sobre o sujeito surdo e a Libras. A coleta dos dados ocorreu por meio de narrativas escritas por estes alunos no início e no final do semestre letivo em que cursaram a disciplina de Libras. As autoras apontaram que os alunos após terem cursado a disciplina de Libras passaram a entender a legitimidade da língua de sinais, e abandonaram o monopolismo oral. Além disso, passaram a entender as pessoas surdas como membros de um grupo cultural. Também deixaram de ver as pessoas surdas como deficientes. As autoras concluíram que a inserção desta disciplina no curso de Pedagogia contribui significativamente para a formação desses professores, bem como com a sua cidadania e inclusão social.

A dissertação de mestrado intitulada Libras na formação de professores: percepções dos alunos e da professora, de Josiane J. F. de Almeida foi defendida em 2012, na Universidade 
DISCIPLINA DE LIBRAS: O QUE AS PESQUISAS ACADÊMICAS DIZEM SOBRE A SUA INSERÇÃO NO ENSINO SUPERIOR?

Estadual de Londrina - UEL. A pesquisadora caracterizou a implementação da disciplina de Libras fazendo uma análise documental do programa desta disciplina no currículo do curso de Pedagogia da UEL. Também investigou os efeitos desta disciplina junto aos graduandos - por meio da aplicação de um questionário - e à professora, realizando entrevista com a mesma. Cabe ressaltar que a pesquisa foi realizada com os alunos das primeiras turmas da disciplina de Libras implantada nos currículos dos cursos da UEL. Em relação ao programa ela identificou que:

[...] os conteúdos e os objetivos focalizaram os aspectos lingüísticos da Libras e o desenvolvimento de atividades práticas pertinentes a referida língua; e estudos relacionados à surdez na perspectiva cultural. As análises do questionário aplicado aos alunos mostraram que muitos, após finalizarem a disciplina de Libras, ainda se sentiam inseguros em receber alunos surdos em suas salas de aula. Os resultados da entrevista com a professora de Libras indicaram sua percepção sobre o principal objetivo da disciplina de Libras como o de sensibilizar os graduandos para o trabalho com alunos surdos por meio do conhecimento da cultura surda e da língua de sinais. (ALMEIDA, 2012, resumo)

A autora conclui que a disciplina de Libras tem muito a contribuir com a formação de professores para a educação inclusiva, especialmente no que se refere aos saberes necessários para a educação do aluno surdo. No entanto, ela aponta algumas dificuldades enfrentadas para a implementação da disciplina com êxito, tais como a baixa carga horária da disciplina, a grande quantidade de alunos por turma, a falta de um Tradutor/Intérprete de Libras-Língua Portuguesa na instituição, entre outras.

A mesma autora publicou com sua Orientadora de Mestrado o artigo A disciplina de Libras na formação inicial de pedagogos: experiência dos graduandos (ALMEIDA; VITALINO, 2012) nos Anais da IX ANPED Sul - Seminário de Pesquisa em Educação da Região Sul. Neste trabalho ela focaliza os efeitos da disciplina, ministrada por uma professora surda, na formação inicial de Pedagogos, partindo do ponto de vista dos graduandos. Os dados foram obtidos através de um questionário composto por 15 perguntas, subdivididas em dois temas, que compreenderam questões referentes à Disciplina de Libras e à Educação/Inclusão de alunos surdos. Entre as principais dificuldades encontradas no decorrer da disciplina, os alunos destacaram aquelas referentes às habilidades específicas para a prática da língua de sinais, à carga horária da disciplina; à falta de um intérprete como apoio durante as aulas, entre outras. De acordo com Almeida e Vitalino (2012, p. 13) "é inegável o papel da disciplina de formar professores regentes 
SANTOS, A. N.; KLEIN, M.

que conheçam a surdez e suas especificidades, que envolvem questões linguísticas, culturais, cognitivas e pedagógicas, além de conhecimentos básicos da língua”.

Também em 2012 as professoras da UFGD e UFMS Grazielly do Nascimento, Sheyla Silva e Janete Nantes publicaram o artigo A disciplina Libras no currículo do Ensino Superior: Desafios e perspectivas para a formação de professores nos Anais do V Congresso Brasileiro de Educação Especial e VII Encontro Nacional dos Pesquisadores da Educação Especial. No artigo elas apresentam uma análise sobre os desafios, perspectivas e a contribuição da disciplina de Libras na formação de professores em tempos de inclusão. Para tanto elas realizaram revisão de literatura, análise de documentos legais que normatizam o ensino de Libras e a educação de surdos no Brasil, pesquisa de campo por meio de aplicação de questionários e depoimentos de acadêmicos acerca da Libras como disciplina no Ensino Superior. Foram aplicados cem questionários a alunos que cursaram a disciplina de Libras, dos cursos de Ciências Sociais, Pedagogia, História e Letras, com dez perguntas semi-estruturadas acerca da disciplina no que se refere à carga-horária, conteúdo e material didático. As autoras entendem que inserir a disciplina de Libras nos currículos dos cursos de licenciatura, conforme determinação do Decreto Federal $n^{\circ}$ 5.626/2005, significa “[...] oferecer conhecimento acerca dos surdos e da Libras para uma atuação profissional favorável e que respeite a diferença linguística do surdo.” (NASCIMENTO, SILVA, NANTES, 2012, p. 12225). As contribuições da inserção da Libras como disciplina no Ensino Superior na formação de professores que atuarão no contexto da inclusão escolar, são segundo as autoras, a compreensão da condição linguística da pessoa surda, da sua cultura e identidade, bem como de suas especificidades educacionais, como exemplo o acesso a comunicação pelo tradutor/intérprete de Libras e o aprendizado da língua portuguesa como segunda língua e, principalmente, do seu papel como professor regente frente ao aluno surdo e ao intérprete na sala de aula. Afirmam, ainda que "Apesar da carga horária da disciplina não ser suficiente para aprender a falar em Libras com proficiência, os depoimentos dos acadêmicos demonstram mudanças significativas de conceitos a respeito da pessoa surda e de sua condição linguística e cultural.” (2012, p. 12235).

No artigo A disciplina de Libras na graduação de pedagogia: contribuições para a formação do professor, Feltrin (2013) faz um relato de sua experiência como docente da disciplina de Libras, expondo seus aspectos curriculares e metodológicos. Segundo a professora 
DISCIPLINA DE LIBRAS: O QUE AS PESQUISAS ACADÊMICAS DIZEM SOBRE A SUA INSERÇÃO NO ENSINO SUPERIOR?

Simone a disciplina de Libras é ofertada no curso de Pedagogia, no $8^{\circ}$ semestre, com carga horária de 72 horas/aula, com média trinta e cinco acadêmicos(as) por turma. O objetivo desta disciplina é desenvolver nos alunos o uso desta comunicação, oportunizando a aprendizagem não só da língua, mas o respeito e a convivência com a diversidade. Quanto à metodologia de ensino a autora afirma utilizar-se de aulas expositivo-dialogadas e de aulas práticas, por meio de diferentes estratégias didáticas. A autora afirma que a disciplina de Libras contribui significativamente para a formação do professor inclusivo.

\subsection{Foco na formação do professor de Libras no Ensino Superior}

Outro grupo de publicações trata, mais especificamente, de análise da formação dos professores responsáveis pelo ensino de Libras. Uma delas é a dissertação de Mestrado Larissa S. Rebouças, intitulada "A prioridade dos docentes surdos para ensinar a disciplina Língua Brasileira de Sinais (LIBRAS) nas instituições de ensino superior após o decreto 5.626/2005”, a qual foi defendida em 2009 na Universidade Federal da Bahia. Neste caso específico, a pesquisadora abordou a condição de ser surdo ou ouvinte dos Professores de Libras nas Universidades, tendo em vista a prioridade das pessoas surdas para o ensino desta língua. A coleta dos dados foi feita por meio de entrevistas com um total de 23 professores, sendo apenas 4 deles ouvintes. A autora sublinha: "Entendo que o ensino de LIBRAS não é vetado às pessoas ouvintes, elas podem exercer a docência desta disciplina desde que sejam fluentes na língua, mantenham contato com a comunidade surda, bem como pratiquem um currículo que estimule a comunicação em LS.” (REBOUÇAS, 2009, p. 115). No entanto, a pesquisadora argumenta em favor da contratação de professores surdos, mesmo que tenham apenas o Ensino Médio, mas que possuam formação de Instrutor ou Multiplicador de Libras, baseando-se no artigo $7^{\circ}$, inciso II, do Decreto Federal $n^{\circ}$ 5.626/2005. Para a autora, a condição de ser surdo e ter a Libras como sua língua nativa já o qualifica para ser professor de Libras, o que ela chama de "legitimidade natural" do professor surdo (REBOUÇAS, 2009, p. 97). Ela ainda aponta a necessidade de que os dirigentes das Instituições de Ensino Superior - IES - se conscientizem da natureza da Libras e do propósito da disciplina, que é, segundo a autora, a prática sinalizada. 
SANTOS, A. N.; KLEIN, M.

A formação de professores para o ensino de Libras também é tema do artigo "Inclusão escolar e a formação de professores para o ensino de Libras (Língua Brasileira de Sinais): do texto oficial ao contexto”, de Tavares e Carvalho (2010). A pesquisa apresentada consistiu na verificação de dez (10) editais de concursos públicos para o ensino de Libras em oito (8) Instituições de Ensino Superior localizadas na região Nordeste, no período de janeiro de 2009 a junho de 2010. Trata-se de uma análise do perfil requerido por essas instituições e sua coerência com o disposto no referido Decreto, além de averiguar as ementas por elas propostas para a disciplina Libras. De acordo com os autores,

Os editais traziam exigências distintas e muitas vezes díspares, de uma instituição para outra, denotando entendimentos diversos sobre o perfil de profissional e de conteúdo a ser trabalhado nesta disciplina. Alguns enfocavam a prática ou o uso da língua, outras pareciam ir mais além, colocando em seu conteúdo de prova, questões ligadas ao funcionamento da língua e dos métodos utilizados na educação dos surdos. (TAVARES; CARVALHO, 2010, p. 4)

Segundo Tavares e Carvalho (2010), esses diferentes entendimentos apresentados nos editais provém das dubiedades suscitadas pelo Decreto Federal no 5.626/2005. Como exemplo eles apontam o artigo $7^{\circ}$ do referido Decreto que define o perfil do docente de Libras para atuar no ensino superior, indicando que o mesmo pode ter apenas formação de nível médio ou formação em qualquer curso de graduação com certificação de proficiência como professor de Libras. No entanto, segundo os autores tal determinação contradiz as Diretrizes Curriculares Nacionais para a formação de professores da Educação Básica, que indicam que para ser professor de uma língua materna ou de língua estrangeira, faz-se necessário a formação em curso de graduação de licenciatura plena em Letras. Tavares e Carvalho sublinham que dos dez editais analisados, “[...] quase $80 \%$ destes exigem o certificado de proficiência em Libras expedido pelo MEC, como regra, quando, segundo o Decreto, esse seria um perfil alternativo a ser utilizado na ausência de docente com título de pós-graduação ou de graduação em Libras, conforme artigo $7^{\circ}$ e seus incisos.” (2010, p. 9). Em relação à formação ou à titulação exigida nos editais para os candidatos ao cargo de professor da disciplina Libras, “[...] as instituições pesquisadas parecem não ter clareza acerca da qualificação mais adequada para o provimento desse cargo. Nos dez editais analisados, se apresentam doze perfis distintos, que vão desde a simples exigência de 
DISCIPLINA DE LIBRAS: O QUE AS PESQUISAS ACADÊMICAS DIZEM SOBRE A SUA INSERÇÃO NO ENSINO SUPERIOR?

graduação, em qualquer área, passando pela pesquisa e experiência docente em Libras, até o mestrado nessa área.” (TAVARES; CARVALHO, 2010, p. 9).

\subsection{Foco na análise dos materiais didáticos para o ensino da disciplina de Libras}

Outro foco das publicações pesquisadas que abordam a disciplina de Libras são os artigos que tratam da produção de materiais didáticos para o ensino da Libras no Ensino Superior para alunos ouvintes. Dentre eles destacamos dois trabalhos publicados pelos professores de Libras da UFPel: "Ensino de Libras na UFPel: memórias da experiência de produção de material didático em interface digital interativa" e "O ensino de Libras para ouvintes: desafios para a produção de material didático" respectivamente nos Anais do VII Seminário Nacional de Linguagens e Ensino - SENALE (ROSA; LEBEDEFF; SANTOS; SILVA, 2012) e nos Anais do VIII Congresso Internacional da ABRALIN - Associação Brasileira de Linguística(ROSA; LEBEDEFF; SANTOS; SILVA, 2013). Em ambos os artigos toma destaque a escassez de materiais didáticos para o ensino da Libras no contexto brasileiro, bem como o fato que ainda são recentes os próprios estudos linguísticos da Libras e as pesquisas sobre o seu ensino para ouvintes. No primeiro trabalho os autores se propõe a problematizar e a compartilhar a experiência da produção de uma proposta de material didático para o ensino de Libras na UFPEL. Eles abordam o processo de produção dos materiais, a partir dos aspectos tecnológicos, explicitando especialmente a elaboração de um Glossário Interativo. Eles argumentam que as principais características de um material para o ensino da Libras para alunos ouvintes são: “[...] 1) o uso de uma linguagem visual capaz de prescindir, ao máximo, da linguagem escrita; 2) potencial comunicativo e 3) tecnologia de fácil manuseio" (ROSA; LEBEDEFF; SANTOS; SILVA, 2012, p. 6). No segundo trabalho, Lebedeff, Santos, Silva e Rosa (2013) se propõem a fazer uma reflexão sobre o ensino de Libras como L2 para ouvintes a partir da experiência de produção de materiais didáticos para a disciplina de Libras, que tomou como base uma abordagem comunicativa. Essa abordagem, segundo os autores, concebe a língua(gem) como um instrumento de comunicação e interação social, e pretende promover vivências do uso real e significativo da língua, para que o aluno possa aprender a interpretar e produzir mensagens dentro 
SANTOS, A. N.; KLEIN, M.

de situações e contextos diversos. A partir da análise dos materiais já produzidos para o ensino de Libras na UFPel, eles concluem que é necessário sinalizar as frases de maneira mais lenta; melhorar a qualidade das filmagens, com a aquisição de filmadoras adequadas à proposta, e, considerando que a Libras é uma língua viso-gestual que se realiza em três dimensões, afirmam que é preciso esmerar-se no enquadramento das imagens, no ângulo da filmadora e, se possível, filmar a mesma sinalização em diferentes ângulos.

$\mathrm{O}$ artigo "O ensino da Libras para ouvintes: análise comparativa de três materiais didáticos”, de Roseli Reis da Silva (2012) também aborda os materiais didáticos para o ensino de Libras, mas não especifica para qual nível de ensino. A autora aponta a problemática da escassez, da falta de estudos e da falta de especificidade para um público-alvo dos materiais didáticos existentes para o ensino de Libras a ouvintes. Ela divide a analise em quatro tópicos que seguem: a) Ensino Comunicativo, b) Atividades/ tarefas, c) Vocabulário e d) Material Visual, baseada em Tomlinson e Masuhara (2005) que tratam da avaliação de materiais didáticos para o ensino de segunda língua, bem como em autores como Richards (2006) que discutem o ensino de língua estrangeira sob a perspectiva da abordagem comunicativa. Ela conclui que "[...] existem atividades, principalmente nos materiais 1 e 2, que apresentam traços de uma abordagem comunicativa, porem, ainda ha muita ênfase no ensino dedutivo da gramática, por meio da sua explicitação e de exercícios para a sua fixação.” (p. 126).

\section{O QUE PODEMOS DIZER DAS PESQUISAS SOBRE A DISCIPLINA DE LIBRAS NO ENSINO SUPERIOR - ALGUMAS CONSIDERAÇÕES}

As pesquisas apresentadas até aqui demonstram que a disciplina de Libras está na "ordem do dia" das discussões atuais acerca da formação de professores, dos estudos curriculares, das políticas públicas, dentre outras áreas às quais os trabalhos encontrados estão vinculados.

Elas se propõem a fazer uma análise curricular. Tal análise consiste, geralmente, em descrições e comparações de planos de ensino de diferentes cursos e/ou de diferentes universidades publicas e/ou particulares de algumas regiões específicas. Esta descrição se dá principalmente quanto aos conteúdos e à carga horária. Das cinco publicações encontradas com o 
DISCIPLINA DE LIBRAS: O QUE AS PESQUISAS ACADÊMICAS DIZEM SOBRE A SUA INSERÇÃO NO ENSINO SUPERIOR?

foco nas análises curriculares, três afirmam que as disciplinas de Libras organizam os conteúdos a partir da divisão entre conteúdos teóricos e conteúdos práticos. No entanto, os artigos se restringem a descrições e comparações, sem aprofundar suas análises.

Foram encontrados muitos trabalhos que analisam as contribuições da disciplina de Libras para a formação de professores para atuar com o aluno surdo na inclusão. Das oito pesquisas publicadas, cinco investigaram as contribuições a partir de entrevista ou questionário com os alunos da disciplina de Libras, aplicado no início e no final do semestre. Todos os artigos indicam contribuições que a disciplina de Libras dá à formação dos professores, bem como à promoção da inclusão dos alunos surdos. As pesquisas inferem que o aluno que cursa a disciplina de Libras aprende a se comunicar em língua de sinais, muda seus conceitos em relação à pessoa surda e passa a respeitar a condição linguística e cultural dos surdos e adquire conhecimentos acerca do processo de aprendizagem dos futuros prováveis alunos surdos. Sendo assim, os artigos argumentam que a disciplina de Libras contribui para a formação de um professor que incluirá o aluno surdo futuramente. No entanto, alguns artigos apresentam ressalvas quanto a pouca carga horária da disciplina. Além disso, destacam que a inserção da disciplina de Libras nos cursos de Licenciatura é um, dentre o muitos elementos para a efetivação da educação inclusiva.

Para além da apresentação de pesquisas que, nos últimos anos, têm como foco a disciplina de Libras, este trabalho possibilita ver que essas pesquisas estão produzindo discursos que tem efeitos na forma como as disciplinas de Libras estão se constituído. Os discursos que circulam nestes artigos e dissertações de mestrado estão produzindo a necessidade de se falar sobre a disciplina de Libras, seja em termos políticos, curriculares, didáticos ou mesmo sobre perfil dos professores e a formação dada aos alunos desta disciplina.

Circulam muitos discursos que produzem a necessidade do aumento da carga horária da disciplina de Libras, e/ou bem como, a necessidade de articulação com outras disciplinas no currículo dos cursos de Licenciatura, especialmente aqueles relacionados à educação inclusiva. Os discursos também indicam que as disciplinas de Libras têm dividido os conteúdos em teóricos (estudos sobre os surdos e sua cultura) e práticos (comunicação em língua de sinais), sendo que em alguns casos, há prevalência de uns sobre os outros. E esta forma de distribuir os conteúdos pode contribuir mais ou menos para a formação de professores que estejam aptos para atender os 
SANTOS, A. N.; KLEIN, M.

futuros alunos surdos em situação de inclusão, o que seria o fim último da disciplina de Libras e grande objetivo do Decreto Federal nº 5.626/2005.

Cabe salientar que além da disciplina de Libras ser o foco das pesquisas citadas acima, ela também tem sido alvo das manifestações da comunidade surda brasileira, que fez apontamentos para a formulação de diretrizes para o ensino de Libras, conforme consta no documento "Propostas para a elaboração de uma política nacional bilíngue para surdos", elaborado pela FENEIS no âmbito do Movimento Surdo em favor da Educação e Cultura Surda:

[...] seis anos após o decreto 5.626/2005, que determinou a existência de disciplinas de Libras na educação básica e em alguns cursos do ensino superior, até hoje não temos ainda as diretrizes dessas disciplinas. Propõe-se a formação - com a participação da Feneis - de um grupo de trabalho de professores surdos já atuantes nas escolas e em universidades públicas, com o objetivo de elaborar propostas para essas diretrizes curriculares a serem apresentadas à Secretaria de Ensino Superior e à Secretaria de Educação Básica do MEC. (CAMPELLO; REZENDE, 2012, p. 15)

Além de circular na comunidade surda, a disciplina de Libras também foi destaque nas discussões promovidas pelo I Encontro Nacional de Professores de Libras no Ensino Superior - I ENPLES - ocorrido no mês de outubro de 2013. O evento foi promovido pelos professores de Libras da Universidade Federal do Ceará e do Instituto Federal de Educação, Ciência e Tecnologia do Ceará. Participaram professores de Libras de diferentes Instituições de Ensino Superior do Brasil. O evento apresentou discussões sobre as políticas públicas e linguísticas da Libras, bem como sobre a formação e a profissionalização do professor de Libras. As mesas foram compostas por professores de Libras de diferentes regiões do Brasil, os quais apresentaram suas experiências, suas trajetórias profissionais, suas práticas no ensino da Libras como L2 e a caracterização da identidade do docente de Libras. Além de palestras e mesas redondas, o evento proporcionou o diálogo entre os professores de Libras em grupos de trabalho, que discutiram sobre como os planos de ensino das disciplinas de Libras estão se configurando, quais conteúdos estão sendo ensinados, quais metodologias estão sendo empregadas, entre outros assuntos.

Assim, é perceptível a efervescência dos discursos em torno da disciplina de Libras, que a estão tematizando e problematizando, bem como produzindo discursos e significados sobre os surdos, sua língua e sua educação. 
DISCIPLINA DE LIBRAS: O QUE AS PESQUISAS ACADÊMICAS DIZEM SOBRE A SUA INSERÇÃO NO ENSINO

SUPERIOR?

\title{
BRAZILIAN SIGN LANGUAGE AS AN ACADEMIC COURSE: WHAT HAS ACADEMIC RESEARCH STATED ABOUT ITS INSERTION IN HIGHER EDUCATION?
}

\begin{abstract}
This paper analyzes how the insertion of Brazilian Sign Language as a course in Higher Education has been a focus of research since the Federal Act nr. 5.626/2005. A search on different research web sites, like Scielo and Google, has led us to dissertations and theses, as well as papers published in books, journals or annals of events. Such productions analyze: the law as a policy requiring the insertion of that course in Higher Education; curricula, considering the teaching program of the courses; the implications of the course in the education of teachers to work in the inclusion of deaf students; the course didactic materials. Discourses about Libras as an academic course have increased and produced meanings about the deaf, their language and education, as well as effects on the course program.
\end{abstract}

Keywords: Libras Subject; Higher Education; Academic Research

\section{ASIGNATURA DE LIBRAS: ¿LO QUE LAS INVESTIGACIONES ACADÉMICAS DICEN SOBRE SU INSERCIÓN EN LA EDUCACIÓN SUPERIOR?}

\section{Resumen}

El artículo examina como lainserción de la asignatura Lengua Brasileña de Señales em la Educación Superior, mediante el Decreto Federal $\mathrm{n}^{\mathrm{o}} 5.626 / 2005$, ha sido el foco de investigaciones. El análisis apunta para investigaciones que abordan esa asignatura insertada em la Educación Superior. Realizamos la búsqueda en diferentes sitios de investigaciones, tales como Scielo y Google, encontrando disertaciones y tesis, así como artículos disponibles em libros, revistas, o actas de congresos. Verificamos que esas producciones analizan: - la legislación, mientras política que obliga la inserción de la asignatura em la Enseñanza Superior; - los 
SANTOS, A. N.; KLEIN, M.

currículos, a partir de planes de enseñanzas de las asignaturas; - las implicaciones de la asignatura em la formación de maestros para actuar com alumnos sordos em la inclusión; - la formación del profesor de Libras em la Educación Superior; - los materiales didácticos para la asignatura de Libras. Son discursos efervescentes alrededor de la asignatura de Libras, produciendo significados sobre los sordos, su lengua y su educación, y efectos em los propios currículos de la asignatura.

Palabras clave: Asignatura De Libras; Educación Superio; Investigaciones Académicas

\section{REFERÊNCIAS}

ALMEIDA, J. J. F. Libras na formação de professores: percepções de alunos e da professora. Dissertação (Mestrado em Educação). Londrina: Universidade Estadual de Londrina, 2012.

ALMEIDA, J. J. F.; VITALINO, C. R. A disciplina de Libras na formação inicial de pedagogos: experiência dos graduandos. In: Anais da IX ANPED Sul - Seminário de Pesquisa em Educação da Região Sul. Caxias do Sul, 2012.

BRASIL. Decreto 5.626 de 22 de dezembro de 2005. Disponível em: [http://portal.mec.gov.br/seesp/arquivos/pdf/dec5626.pdf] Acesso em: 15/10/2011.

CAMPELLO, A. R. S.; REZENDE, P. L. F. Propostas para a elaboração de uma Política Nacional de Educação Bilíngue para Surdos. Rio de Janeiro: FENEIS - Federação Nacional de Educação e Integração dos Surdos, 2012.

FELTRIN, S. G. N. A disciplina de Libras na graduação de pedagogia: contribuições para a formação do professor. In: FERREIRA, R. B.; DIAS, A. T. B. B. (Orgs). I Coletânea de experiências de ensino/aprendizagem dos docentes dos cursos de graduação da UNESC. Criciúma, SC: UNESC, 2013.

FOSSILE, D. K.; VENÂNCIO, S. O. C. Perspectiva sociolinguística da inclusão da Libras no ensino superior. In: Fórum Linguístico, Florianópolis, v. 10, n. 2, p. 116-125, abr./jun. 2013 (p. 116 - 125) http://dx.doi.org/10.5007/1984-8412.2013v10n2p116. Acesso em: 14 Set. de 2014.

LACERDA, C. B. F.; CAPORALI, S. A; LODI, A. C. Questões preliminares sobre o ensino de língua de sinais a ouvintes: reflexões sobre a prática. In: Distúrbios da Comunicação. São Paulo, 16(1): 53-63, abril, 2004. Disponível em: http://revistas.pucsp.br/index.php/dic/article/view/11620. Acesso em: 14 Set. de 2014. 
DISCIPLINA DE LIBRAS: O QUE AS PESQUISAS ACADÊMICAS DIZEM SOBRE A SUA INSERÇÃO NO ENSINO SUPERIOR?

LEBEDEFF, T. B.; ROSA, F. S.. SANTOS, A. N.; SILVA, I. G. Ensino de Libras na UFPel: memórias da experiência de produção de material didático em interface digital interativa. In: VII Seminário Nacional sobre Linguagens e Ensino, 2012, Pelotas. Anais do VII SENALE. Pelotas: Editora da Universidade Católica de Pelotas, 2012.

LEBEDEFF, T. B.; ROSA, F. S. SANTOS, A. N; SILVA, I. G.. O ensino de Libras para ouvintes: desafios para a produção de material didático. Anais do VIII Congresso Internacional da ABRALIN - Associação Brasileira de Linguística. Natal: UFRN, 2013.

LEMOS, A. M.; CHAVES, E. P. A disciplina de Libras no ensino superior: da proposição à prática de ensino como segunda língua. Anais do XVI ENDIPE - Encontro Nacional de Didática e Práticas de Ensino - UNICAMP - Campinas - 2012. Disponível em: http://www2.unimep.br/endipe/2190c.pdf. Acesso em: 15/07/2014.

LODI, A. C. B.; NOGUEIRA, E. A. Língua Brasileira de Sinais nos Cursos de Licenciatura: investigando o processo de formação de professores. In: Biblioteca Virtual da FAPESP. CDi/FAPESP - Centro de Documentação e Informação da Fundação de Amparo à Pesquisa do Estado de São Paulo, 2011. Disponível em: http://www.bv.fapesp.br/pt/bolsas/73388/linguabrasileira-de-sinais-nos-cursos-de-licenciatura-investigando-o-processo-de-formacao-de-profes/. Acesso em: 22 Set. de 2014.

MACHADO, L. M. C. V.; LÍRIO, L. M. A disciplina de libras e a formação inicial dos professores: experiências dos alunos de graduação em pedagogia na Universidade Federal do Espírito Santo. Revista FACEVV. n. 6. Vila Velha, 2011. Disponível em: http://www.facevv.edu.br/Revista/06/lucyenne\%20matos.pdf. Acesso em: 09 Set. de 2014.

MARTINS, V. R. O. Análise das vantagens e desvantagens da Libras como disciplina curricular no ensino superior. Cadernos do CEOM- Ano 21, n. 28 - Memória, História e Educação Chapecó: Argos, 2008. Disponível:

http://bell.unochapeco.edu.br/revistas/index.php/rcc/article/view/161. Acesso em: 20 Set. de 2014.

MARTINS, V. R. O. O acontecimento do ensino de libras - diferenças e resistências. In: ALBRES, N. A. Libras em estudo: ensino-aprendizagem. São Paulo: FENEIS-SP, 2012.

MERCADO, E. A. O significado e implicações da inserção de libras na matriz curricular do curso de pedagogia. In: ALBRES, N. A. Libras em estudo: ensino-aprendizagem. São Paulo: FENEISSP, 2012.

NASCIMENTO, G. V. S.; SILVA, S. C. A. Matoso; NANTES, Janete de Melo. A disciplina Libras no currículo do Ensino Superior: Desafios e perspectivas para a formação de professores. 
SANTOS, A. N.; KLEIN, M.

In: Anais do V Congresso Brasileiro de Educação Especial e VII Encontro Nacional dos Pesquisadores da Educação Especial. São Carlos: UFSCar, 2012.

PEREIRA, T. L. Os desafios da implementação do ensino de Libras no Ensino Superior. Dissertação (Mestrado em Educação). Ribeirão Preto: Centro Universitário Moura Lacerda de Ribeirão Preto, 2008. 94 folhas.

REBOUÇAS, L. S. A prioridade dos docentes surdos para ensinar a disciplina Libras (Língua brasileira de sinais) nas instituições de ensino superior após o decreto 5626/2005. Dissertação (Mestrado em Educação). Salvador: Universidade Federal da Bahia, 2009. 171 folhas.

ROSSI, R. A. A Libras como disciplina no ensino superior. Revista de Educação. v, 13, n. 15, Anhanguera Educacional, Valinhos-SP, 2010. Disponível em:

[http://www.pgsskroton.com.br/seer/index.php/educ/article/viewFile/1867/1772]. Acesso em: 20 Set. de 2014.

SANTOS, A. N.; SILVA, I. G.; ROSA, F. S.; LEBEDEFF, T. B.. O ensino de Libras para ouvintes: desafios para a produção de material didático. In: VIII Congresso Internacional da Abralin, 2012, Natal. Caderno de Programação e Resumos do VIII Congresso Internacional e XXI Instituto da Abralin. Natal: Ideia Editora, 2012b.

SILVA, R. R. O ensino da LIBRAS para ouvintes: análise comparativa de três materiais didáticos. In: ALBRES, N. A. (Org.). Libras em estudo: ensino-aprendizagem. 1ed.São Paulo: FENEIS, 2012.

SOUZA, R. M.; GALLO, S. Entre maioridades e minoridades: língua, cultura e política no plural. Políticas Educativas - Revista do Programa Políticas Educativas do Núcleo Disciplinário Educação para a Integração da Associação de Universidades Grupo Montevideo, v. 1, Porto Alegre-RS. 2007. Disponível em: [http://seer.ufrgs.br/Poled/article/view/18258]. Acesso em: 18 Nov. de 2014.

TAVARES, I. M. S.; CARVALHO, T. S. S. Inclusão escolar e a formação de professores para o ensino de Libras (Língua brasileira de sinais): do texto oficial ao contexto. In: V EPEAL Pesquisa em Educação: desenvolvimento, ética e responsabilidade social. Maceió: 2010.

VITALINO, C. R.; DALL'ACQUA, M. J. C.; BROCHADO, S. M. D. A disciplina de Língua Brasileira de Sinais nos currículos dos cursos de Pedagogia. Boletim técnico do Senac: a revista da educação profissional. Rio de Janeiro: Senac/Departamento Nacional/Gerência de Marketing e Comunicação - Vol. 39, n. 2, maio/ago, 2013. Disponível em: http://www.senac.br/media/42510/os_boletim_web_7.pdf. Acesso em: 20 Nov. de 2014.

Data de recebimento: 31/05/2015

Data de aceite: 25/08/2015 